Reference: Li Y, Spearpoint M J. Analysis of vehicle fire statistics in New Zealand parking buildings. Fire Technology, Vol. 43, No. 2, 2007, pp.93-106.

\title{
Analysis of vehicle fire statistics in New Zealand parking buildings
}

\author{
Yuguang Li, CSIRO, North Ryde, Sydney, Australia. \\ Michael Spearpoint ${ }^{1}$, Department of Civil Engineering, University of Canterbury, \\ New Zealand.
}

\begin{abstract}
The risk of fire in parking buildings is dependant on the probability of a fire occurring and the severity of the fire. This paper reviews the research data available on vehicle fires and suggests the severity of such a fire for a risk analysis. The paper then examines the historical data for vehicle fires in New Zealand parking buildings from 1995 to 2003 to determine the probability of the occurrence of such fires and the likelihood of multiple vehicle involvement. It is found that annual vehicle fire frequencies in parking buildings are generally lower than those in buildings of other occupancies but increases with the annual usage ratio.
\end{abstract}

Keywords: Vehicle fires; Parking buildings; Statistical analysis.

\section{INTRODUCTION}

\subsection{Background}

The risk of fire in parking buildings and the necessary fire protection measures are recurring topics of discussion amongst the fire protection engineering community. For example, there is debate over the appropriateness of sprinkler provision and whether smoke extraction either by natural or mechanical means is required. Questions are

\footnotetext{
${ }^{1}$ Corresponding author.
} 
also posed regarding whether such systems are necessary for the different types of parking structure commonly found in use and what is their impact on life and property safety. Many of these questions could potentially be addressed through risk analysis if sufficient, relevant data is made available.

Risk is typically defined as a function of the probability of an event occurring and the consequence (or severity) of the event [1]. Therefore in order to conduct a risk analysis of parking building fires it is necessary to determine the probability of a vehicle fire occurring and the severity of the consequent fire. The severity of the fire will depend on the materials involved which is likely related to the age of the vehicle. Furthermore the severity is going to be affected by the probability of the fire spreading to adjacent vehicles or other combustibles.

To aid in risk analysis of fires in parking buildings, this paper presents a review of vehicle fire severity followed by an analysis of parking building vehicle fire statistics in New Zealand with a comparison of results from overseas studies. The paper then evaluates fire frequencies in parking buildings and considers the probability of fire spread to neighbouring vehicles. The results of this paper have been used to conduct a cost-benefit analysis of sprinkler systems for the property protection of parking structures [2].

\subsection{Parking buildings}

In this paper parking buildings are considered to be those structures that are used for the parking of multiple motor vehicles and do not include individual private garages, vehicle repairers, sales showrooms etc. In general parking buildings can be either one of two types: private or public. The private type is generally for people specifically entitled to park in the building, whereas the public type is for the use of any member of the public. Vehicles in these buildings are typically private passenger cars or small utility trucks although other larger vehicles may also occasionally be present.

A parking building can be either single level or a multi-storied structure and either be a standalone building or a structure adjacent to or above/below another occupancy. Steel and concrete are the most commonly used materials for parking building 
construction. The fire safety requirements, including structural fire ratings and provision of fire protection system such as sprinklers, vary between different building codes $[3,4]$. The structure of a parking building can be classified as an open or a closed type according to the ventilation conditions and building codes often define the openness of a parking building.

\section{FIRE SEVERITY OF VEHICLE FIRES}

The severity component of the risk assessment can be characterised by the heat release rate (HRR) of one or more vehicles. Table 1 lists a range of approximate maximum heat release rate values quoted by Ingason [5] and Shipp [6] for various types of vehicles. The HRR figures from Ingason were for road tunnel ventilation conditions.

\begin{tabular}{lcc}
\hline Type of vehicle/s & \multicolumn{2}{c}{ Maximum HRR (MW) } \\
& Ingason [5] & Shipp [6] \\
\hline Small passenger car & 2.5 & 8 \\
Large passenger car & 5 & - \\
2-3 passenger cars & 8 & - \\
Van & 15 & 17 \\
Truck & - & - \\
Bus & 20 & 30 \\
School bus & - & - \\
Lorry with burning goods (general case) & $20-30$ & $13-50$ \\
Train & - & 35 \\
Subway coach & - & 120 \\
Heavy goods vehicle (HGV) & - & - \\
Petrol tanker & 200 & \\
\hline
\end{tabular}

Table 1: Maximum HRR of vehicle fires.

Figure 1 shows various HRR curves from the literature; along with slow and medium t-squared fire HRR curves [7] for comparison. The three tests reported by Mangs and Keski-Rahkonen [8] gave similar HRR results and only Test 2 is shown on Figure 1. The study described by Schleich et al. [9] is represented by their proposed reference HRR curve. Single vehicle fire tests by Steinert [10] yielded relatively low HRR, hence only Test 3 was shown to represent this work. The HRR curve for Maestro car by Shipp and Spearpoint [11] and the reference HRR curve by Schleich et al. [9] show almost same peak HRR value (about $8 \mathrm{MW}$ ); this peak value is also higher than 
other tests shown in Figure 1. In fact, the Maestro car test involved fuel spill from the petrol tank and thus caused the relatively high HRR peak reached 10 minutes earlier than the reference HRR curve. The peak HRR values from other tests are all less than 5 MW.

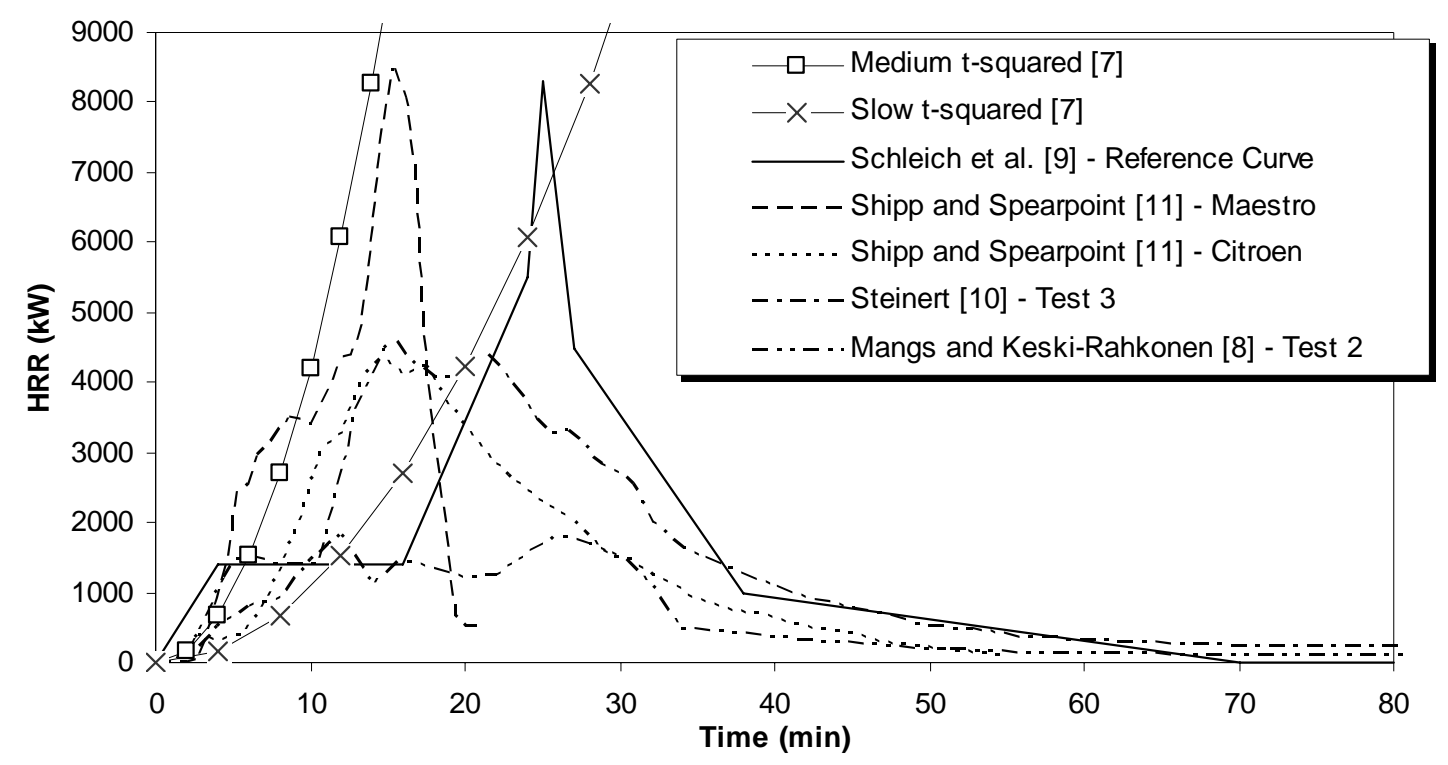

Figure 1. Comparison of HRR curves from various car fire experiments.

Other vehicle fire data is available in the literature, however the vehicle fire test carried out by Stroup et al. [12] was not allowed to go to a full burnout and hence not shown for comparison. Similarly, the tests by Santrock [13] are also not shown for the same reason. Additional HRR data for transport vehicles and components can also be found in Babrauskas [14] where curves for half a tram car and vehicle seatings are illustrated.

From Figure 1, it can be seen that the Maestro car HRR curve can be represented by a medium t-squared fire, while Schleich's reference HRR curve follows a slow tsquared fire. All other HRR curves fit between slow and medium t-squared fires. A medium growth rate seems to be appropriate for a t-squared vehicle design fire with a peak value of $8 \mathrm{MW}$ used for a worst case scenario.

It should be noted that the HRR data discussed here are for passenger vehicles only. The studies by BHP [15], Schleich et al. [9] and Kitano et al. [16] all suggest the 
potential for fire spread between vehicles in a closed car park situation, therefore the fire spread is to be considered in the design fire for this type of car park.

There appears to be a trend that more modern cars yield a higher maximum HRR than older generation cars when involved in fire. Ingason [5] observed a tendency of maximum HRR increasing linearly with the total energy to be released from passenger cars, and further proposed that an average increase of $0.7 \mathrm{MW}$ in maximum HRR can be expected from one GJ of energy. This value is within the range of HRR versus energy (0.55 to $0.85 \mathrm{MW} / \mathrm{GJ})$ shown by Steinert [10].

\section{STATISTICAL ANALYSIS}

\subsection{Background}

The statistical analysis presented in this paper provides an examination of the fire incidents which involved vehicles and occurred in parking buildings throughout New Zealand during the eight-year period from 1995 to 2003. The analysis of these fire incidents was based on the vehicle fire statistical data extracted from Fire Incident Reporting System (FIRS) database maintained by New Zealand Fire Service.

A vehicle in the statistics refers to all vehicle types listed in the following groups under the category of "Mobile Property Type" as defined in New Zealand Fire Service Fire Incident Reporting System Instruction \& Coding Manual [17]. Vehicle types include "Passenger, Road, Transport Vehicles"; "Freight, Road, Transport Vehicles"; and "Special and Miscellaneous Mobile Property". A parking building is defined as those in the "Mobile Property Storage and Parking" group, under the category of "Specific Property Use" in the FIRS coding manual.

It is important to note that the FIRS database records each individual vehicle fire as a separate record even where several vehicles are involved in a single incident. During the eight-year period there were on average around 3,370 vehicle fires per year in New Zealand. The New Zealand Fire Service attended a total of 101 recorded vehicle fires in parking buildings, giving an average of approximately 12.6 fires per year. 
Information from the New Zealand Fire Service shows that there has been no recorded fire fatality in a parking building in New Zealand, although there are approximately two injuries of mainly minor burns each year caused by fires in parking buildings. In a US study of 400 parking building fires conducted by Denda [18] there were no reported fatalities but five fire-fighters and three civilians were injured. Similarly, in the study of 395 fires in US and Canadian parking structures undertaken by Harris [19] it was found that there was no loss of life or injuries due to fire in the parking structures surveyed. The review of car fires in car parks in Europe completed by Joyeux [20] also identified cases where people were injured but no fatalities were recorded.

\subsection{Parking Building and Vehicle Types}

The breakdown of all vehicle fires in New Zealand parking buildings from 1995 to 2003, according to the FIRS coding definitions, is shown in Figure 2. The largest group of parking buildings where vehicle fires occurred was "Single Level Covered Private Fleet Carpark", which accounted for 61 incidents. This was also the only group for private parking buildings as defined in FIRS database and the remaining 40 incidents were distributed amongst the various categories of public parking buildings.

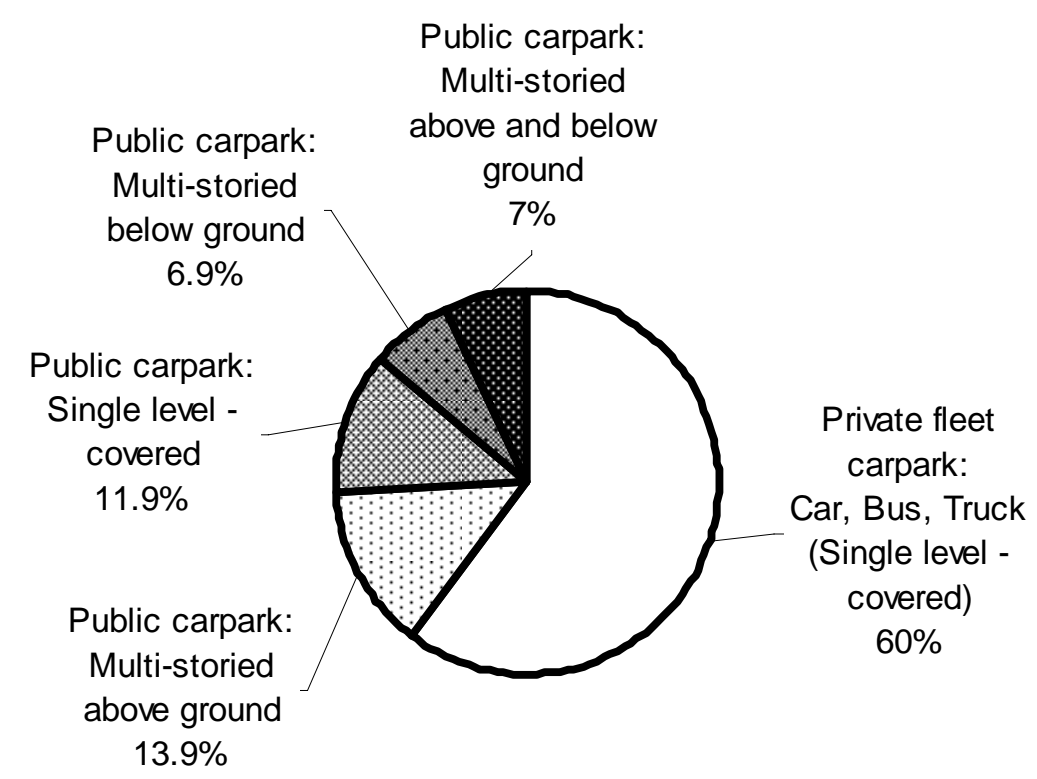

Figure 2. Specific type of parking buildings where vehicles were involved in fires, 1995 - 2003. 
Figure 3 illustrates the breakdown of type of vehicles involved in fire incidents in New Zealand parking buildings from 1995 to 2003. The largest group of vehicle types was "Car, Taxi and Ambulance" which account for 57 vehicle fires. This was followed by the "Unknown" group (22.8\%), "Other Vehicles" (14.9\%) and "Bus" $(5.9 \%)$. The "Other Vehicles" group included "Truck of one tonne and over and fire appliances" (9.9\%); "Light truck under one tonne, ute, van and wagon" (4\%); and "Waste container, bin, compacter and dumper" (1\%).

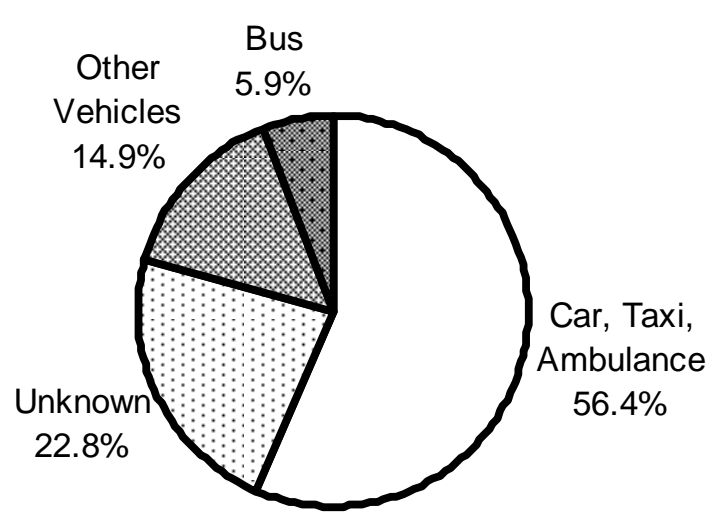

Figure 3. Type of vehicles involved in fires in parking buildings, 1995 - 2003.

\subsection{Supposed Causes of Vehicles Fires in Parking Buildings}

The supposed causes of vehicle fires in New Zealand parking buildings can be divided into two broad categories: "Deliberately Lit" fire and "Accidental" fire. The latter group further includes five groups, which are "Electrical Faults", "Mechanical Failure or Malfunction”, “Carelessness", “Unknown” and "Others” as shown in Figure 4.

Of the 61 vehicle fires in private parking buildings, fifteen fires were deliberately lit, of which ten incidents were unlawful and five incidents were suspicious. The difference between unlawful and suspicious is the level of confidence in determining wether the fire cause is deliberately lit during the coding. Of the 40 vehicle fires in public parking buildings, twelve of these fires were deliberately lit, of which six were unlawful and other six were suspicious. 


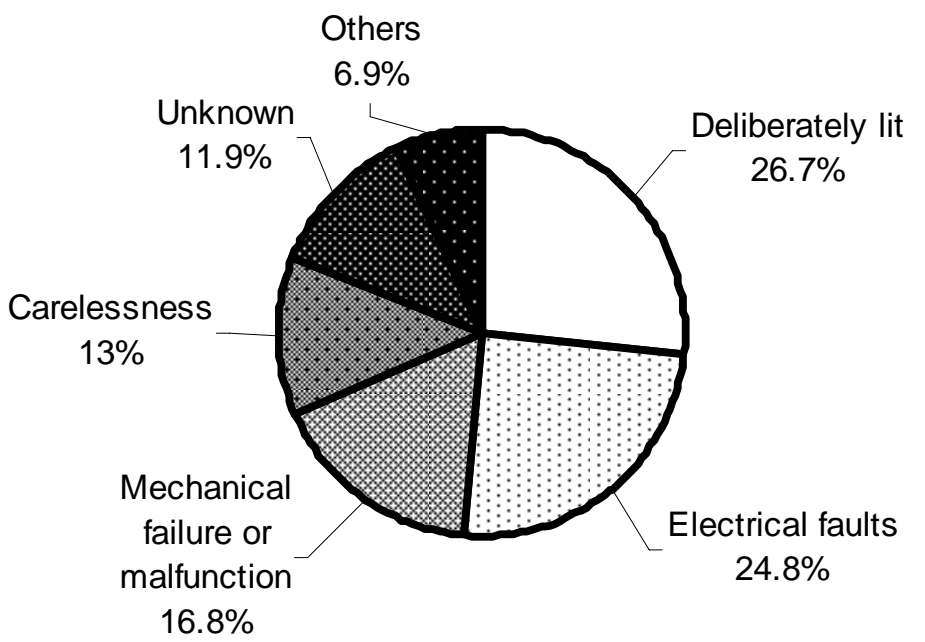

Figure 4. Supposed causes of vehicles fires in New Zealand parking buildings, 1995 - 2003.

The statistics from overseas sources indicate that arson, electrical faults and fuel leaks are the common causes for vehicle fires (Table 2). These finds are similar to the trend found in the New Zealand statistics in this paper, where three leading causes of vehicle fires in parking buildings were "Deliberately lit", "Electrical faults" and "Mechanical failure or malfunction". For New Zealand statistics, the fuel leak cause was included in the "Mechanical failure or malfunction" category.

\begin{tabular}{|c|c|c|c|c|}
\hline \multirow[b]{2}{*}{ Rank } & \multicolumn{4}{|c|}{ Fire Causes } \\
\hline & $\begin{array}{l}\text { New Zealand } \\
\text { Parking } \\
\text { Building } \\
\text { Vehicle Fires } \\
\text { (1995 - 2003) }\end{array}$ & $\begin{array}{c}\text { UK Vehicle } \\
\text { Fires [21] } \\
\text { (1987) }\end{array}$ & $\begin{array}{l}\text { US Passenger } \\
\text { Road Vehicle } \\
\text { Fires [22] } \\
\text { (1994 - 1998) }\end{array}$ & $\begin{array}{c}\text { US Highway } \\
\text { Vehicle Fires } \\
\text { [23] } \\
\text { (1998) }\end{array}$ \\
\hline 1 & Deliberately lit & $\begin{array}{c}\text { Deliberate/possible } \\
\text { deliberate }\end{array}$ & $\begin{array}{l}\text { Part failure, } \\
\text { leak or break }\end{array}$ & $\begin{array}{l}\text { Mechanical or } \\
\text { design problems }\end{array}$ \\
\hline 2 & Electrical faults & $\begin{array}{l}\text { Electrical appliances } \\
\text { \& installations }\end{array}$ & $\begin{array}{l}\text { Circuit or } \\
\text { ground fault }\end{array}$ & Arson \\
\hline 3 & $\begin{array}{l}\text { Mechanical } \\
\text { failure or } \\
\text { malfunction }\end{array}$ & $\begin{array}{l}\text { Oiled \& petrol } \\
\text { fuelled appliances } \\
\text { and installations }\end{array}$ & $\begin{array}{l}\text { Incendiary or } \\
\text { suspicious }\end{array}$ & Carelessness \\
\hline
\end{tabular}

Table 2. Comparison of vehicle fire causes. 
In 1981, three leading sources of ignition of vehicle fires in the UK ranked by the number of incidents were "Electrical appliances \& installations", "Oiled \& petrol fuelled appliances and installations", and "Deliberate/possible deliberate". By 1987, the "Deliberate/possible deliberate" cause became the leading source of ignition, followed by "Electrical appliances \& installations" and "Oiled \& petrol fuelled appliances and installations" [21]. This 1987 figure in the UK appears to be similar to the New Zealand statistics.

From 1994 to 1998, the three leading ignition factors of passenger road vehicles in the US were "Part failure, leak or break" (18.8\%); "Short circuit or ground fault" (18.4\%); and "Incendiary or suspicious" (17.1\%) according to the study by Ahrens [22]. The leading cause of highway vehicle fires in 1998 was "Mechanical or design problems", followed by "Arson" and "Carelessness" as the second and third cause respectively [23]. Again, the leading fire causes in the US were similar to those in New Zealand found in this paper, although the fire causes ranked by the number of incidents were in different order for both countries. It should be noted that the New Zealand statistics in this paper are only for the vehicle fires in parking buildings whereas the international statistics are for general vehicle fires on the road.

\subsection{Fire Spread Between Vehicles}

Figure 5 illustrates the vehicle fires in New Zealand parking buildings by number of vehicles involved due to a single ignition between 1995 and 2003. There were a total of eight vehicles involved in three multiple vehicle fire incidents and these fires all occurred in private parking buildings. Since there were a total of 101 vehicle fires in parking buildings the actual number of fire incidents in parking buildings involving vehicles was 96, which included 93 single vehicle fire incidents and three multiple vehicle fire incidents. Therefore the average number of fire incidents in New Zealand parking buildings, where vehicles were involved, was 12 each year. 


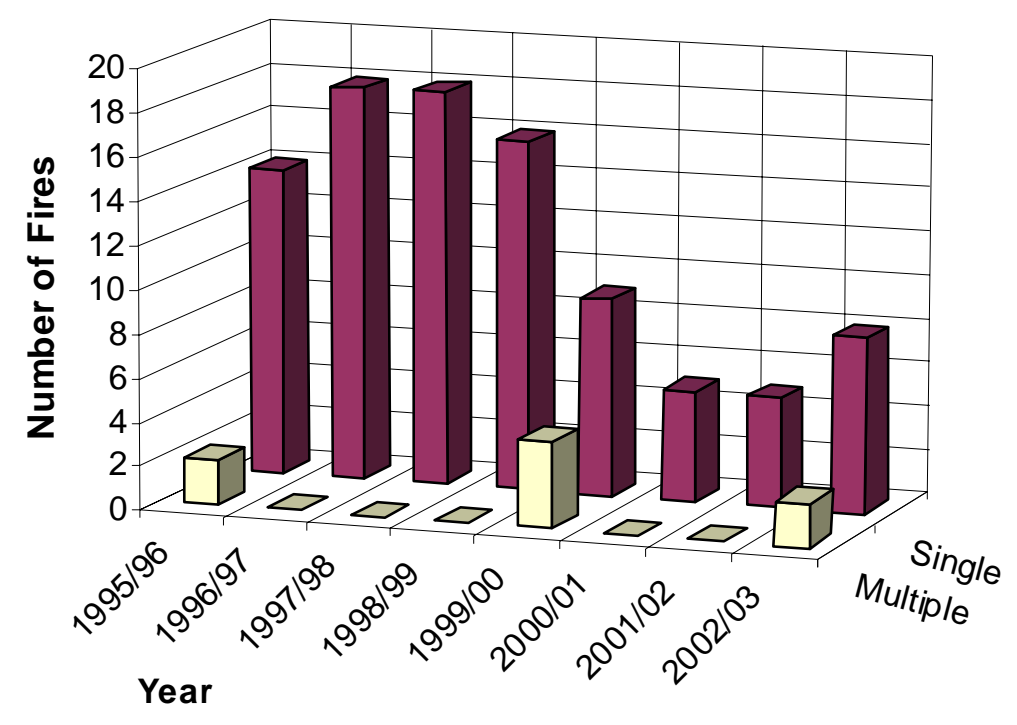

Figure 5. Vehicles fires in parking buildings by number of vehicles involved, $1995-2003$.

There were two incidents where two vehicles were involved in the parking building fire simultaneously; these two incidents occurred in the year of 1995/1996 and 2002/2003 respectively. One incident was caused by a deliberately lit fire, while the fire cause for the other incident was accidental. One other recorded incident involved four vehicles in the year of 1999/2000 and this fire started from a vehicle with recorded type as light truck (under one tonne, ute, van, and wagon) then spread to three buses. The fire cause for this incident was accidental.

The above statistics show that approximately $3 \%$ of the vehicle fire incidents in New Zealand parking buildings involved multiple vehicles which is lower than values published elsewhere. Denda [18] found that $7 \%$ of vehicle fire incidents in US parking structures involved more than one car. It was established that most of the multiple vehicle fires involved two adjacent vehicles, with one case involving three vehicles and another involving four vehicles. Joyeux [20] found that in underground (closed) car parks in Paris, around 15\% of fires that were due to cars had more than one vehicle involved, with $97.9 \%$ of cases having less than four cars and a maximum of seven cars in one incident. For upper structure car parks it was found that $20 \%$ of fires that were due to cars had more than one vehicle involved but the maximum was 
only three cars. Joyeux assumed that the upper structure car parks were representative of open car parks as most would likely be of this type of design.

\subsection{Age of Vehicles Involved in Parking Building Fires}

The FIRS database reports the year of vehicle fire incident and sporadically records the year of manufacture of the vehicle involved. The year of manufacture was recorded for 52 vehicle fires out of a total of 101 vehicle fires in parking buildings. The ages of these vehicles were therefore obtained by subtracting the year of manufacture from the year of fire incident.

Figure 6 shows the distribution of recorded age of vehicles involved in the parking building fires compared with the age distribution for all registered vehicles in New Zealand as at $1^{\text {st }}$ January 1998 [24]. It was assumed that the distribution of vehicle age for national fleet in 1998 can represent the trend in New Zealand in the eight-year period considered in this paper and that the age distribution of vehicles in parking garages is similar to that for the national fleet.

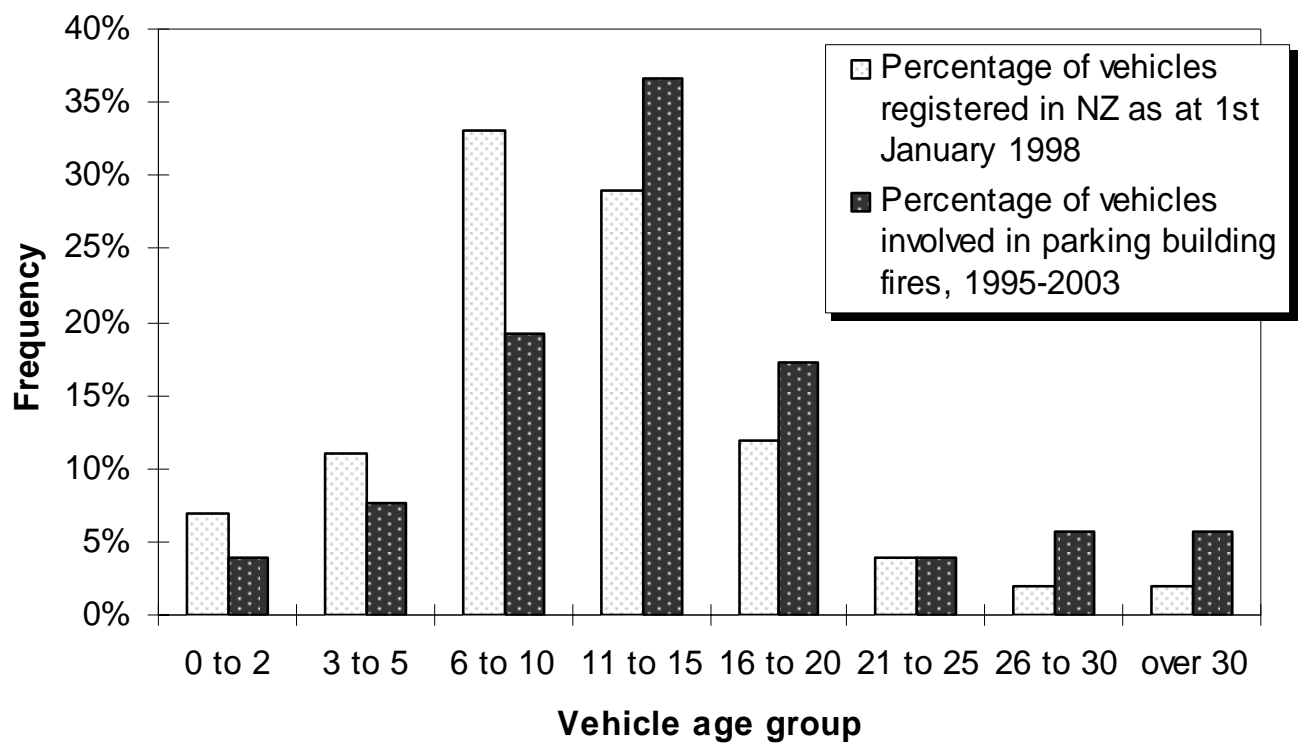

Figure 6. Distribution comparison between age of vehicles involved in parking building fires and age of all registered vehicles. 
The average recorded age of vehicles involved in New Zealand parking building fires was found to be 14.3 years old whereas the overall average vehicle age in this period was calculated as 14.2 years. Figure 6 shows that the vehicles of 11-15 years old were the largest group involved in parking building fire. Moore [25] found that the largest percentage of vehicle fires in UK happened in vehicles of eight years old, which is lower than the figure in New Zealand. This difference can possibly be due to the fact that the vehicle ages in New Zealand, with an average age of 14.2 years old, are likely to be older than in the UK. For example between 1999 and 2001, 51\% of the main or only car or light van normally available to a household in the UK was more than six years old [26] compared with $82 \%$ of vehicles registered in New Zealand.

Figure 6 indicates a correlation between the age of vehicle and probability of vehicle involved in fire. The percentage of vehicles involved in fires with ages less than 11 years old was lower than the percentage of vehicles in the same age group from national fleet; conversely, the percentage of vehicles involved in fire with ages equal to or more than 11 years old was higher than the percentage of vehicles in the same age group from national fleet. It therefore appears that the probability of a vehicle involved in parking building fire rises with the increase of the vehicle age. A 1973 national survey of motor vehicle fires in the United States [27] found a similar trend and indicated that a vehicle of ten years old or more was four times more likely to be involved in fire than a vehicle less than three years old. In New Zealand from 1995 to 2003, a vehicle equal to or more than 11 years old was approximately two and half times more likely to be involved in parking building fires than a vehicle less than three years old. This value of 2.5 was obtained by dividing the percentage ratio for vehicles equal to or more than 11 years old by the percentage ratio for vehicles less than three years old; the percentage ratio for each age group was the ratio between the percentage of vehicles involved in fire and the percentage of vehicles from national fleet. 


\section{VEHICLE FIRE FREQUENCIES IN PARKING BUILDINGS}

\subsection{Vehicle Fire Frequency per Vehicle Visit}

The primary purpose of the parking building is for the temporary storage of vehicles. Hence the number of vehicle visits to the parking building would significantly affect the fire frequency, based on the assumption that the ignition probability of each vehicle visiting the parking building is the same. Chandler and Shipp [28] suggested that the occurrence of a vehicle fire is not time related if the vehicle engine has been on or off for more than 20 minutes. It is therefore appropriate to relate the fire frequency to the number of vehicle visits to a parking building for the purpose of a risk analysis of vehicle fires in parking buildings. In this paper, the vehicle fire frequency in New Zealand parking building is obtained from annual vehicle visits in New Zealand parking building and annual vehicle fire occurrence.

The concept of annual usage ratio is proposed and it is defined as annual vehicle visits to a particular parking building divided by total number of parking spaces in this parking building. This represents the annual vehicle turnover rate in a particular parking building and also expresses the annual average number of vehicle visits to one parking space in the building. The parking building operators in New Zealand generally keep the yearly record of total vehicle visits into their parking buildings but the information is not easily accessible for reasons of commercial sensitivity. To obtain an estimate of likely annual usage ratios it was found that the number of car parking visits to Christchurch City Council's public parking buildings was $1,115,000$ a year in 2003 [29]. The number of the parking bays in these buildings was 3,164

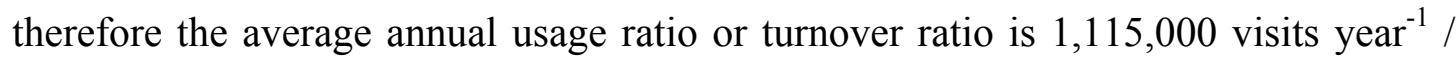
3,164 (space) $\approx 350$ visits per year.

The product of this annual usage ratio and total number of parking spaces in New Zealand yields the number of total vehicle visits. The number of parking spaces in parking buildings and registered vehicles for two major cities were used to predict the total number of parking spaces in New Zealand, based on the total number of vehicles registered in New Zealand. The average value was approximately 200,000 spaces and this was used for the determination of vehicle fire frequency in parking buildings in New Zealand. The total annual vehicle visits to New Zealand parking buildings can 
hence be estimated as 200,000 (spaces) $\times 350$ visits per year $=70,000,000$ visit per year. Since the average number of fire incidents in New Zealand parking buildings where vehicles were involved is 12 each year, the frequency of vehicle fires in the parking building for each vehicle visit is then 12 year $^{-1} / 70,000,000$ visits year ${ }^{-1}=$ $1.71 \times 10^{-7}$ visit $^{-1}$

\subsection{Comparison of Annual Fire Frequencies}

For a parking building, the average floor area per one parking space is defined as the Efficiency [30]. As of 2000, the goal of most parking building designs in the US was to achieve an Efficiency of 28 to $30 \mathrm{~m}^{2} /$ space ( 300 to $325 \mathrm{ft}^{2} /$ space). The number of parking spaces in a parking building can therefore be expressed by dividing the total floor area by Efficiency $(A / P)$. An Efficiency value of $29 \mathrm{~m}^{2} /$ space was used for analysis of the parking building in this paper. The product of annual usage ratio $(R)$ and number of parking spaces $(A / P)$ then yields the annual vehicle visits. Finally, the product of annual vehicle visits and vehicle fire frequency per visit give the annual fire frequency in a parking building. Thus the vehicle fire frequency $(F)$ in a New Zealand parking building might be given as:

$$
F=f \times R \times(A / P)
$$

Equation (1) indicates that vehicle fire frequency in the parking building is linear to the annual usage ratio, for a particular parking building with a specified total floor area.

Fire frequency in a building can be expressed by the following Equation (2), based on a study by Ramachandran [31] where

$$
F=K \times A^{\alpha}
$$

The values for $K$ and $\alpha$ for occupancies of all manufacturing industry, storage and offices are listed in Table 3 taken from Rasbash et al. [32]. Figure 7 shows a plot for the occupancies given in Table 3 using Equation (2) compared with the fire frequencies for parking buildings using Equation (1) for three annual usage ratios: 350, 1,000 and 10,000 where the value of 350 represents the annual usage ratio from the 
statistics related to Christchurch City Council's parking buildings and other values are selected to investigate the sensitivity of Equation (1). Since the parking building analysis is dependant on a relatively small sample of incidents, the plot shows the variability for plus and minus one standard deviation of fire incidents in New Zealand parking buildings. Figure 7 shows that using the simple linear relationship, the fire frequencies in the parking building are lower than those in the buildings of other occupancies when annual usage ratio is relatively low and rises with the increase of annual usage ratio.

\begin{tabular}{l|ccc}
\hline Occupancy & $\begin{array}{c}\text { All manufacturing } \\
\text { industry }\end{array}$ & Storage & Offices \\
\hline$K$ & $1.70 \times 10^{-3}$ & $6.70 \times 10^{-4}$ & $5.90 \times 10^{-5}$ \\
$\alpha$ & 0.53 & 0.5 & 0.9 \\
\hline
\end{tabular}

Table 3. Constants of $K$ and $\alpha$ for various occupancies, reproduced from Rasbash et al. [32].

Since a simple linear relationship for the fire frequency in parking buildings has been assumed then, using Equation (2) and $\alpha=1$, the values for $K$ can be obtained for each annual usage ratio. The constant $K$ was found to be $2.0 \times 10^{-6}(R=350), 6.0 \times 10^{-6}$ $(R=1,000)$ and $6.0 \times 10^{-5}(R=10,000)$. Clearly the assumption that fire frequency in parking buildings has a linear relationship with regard to floor area is a simplification that deviates from Ramachandran's assertion that fire frequency is non-linear with floor area. Statistical data from actual fires may show that this linear relationship is not the case, however, no values for $K$ and $\alpha$ for parking buildings were identified in the literature. 


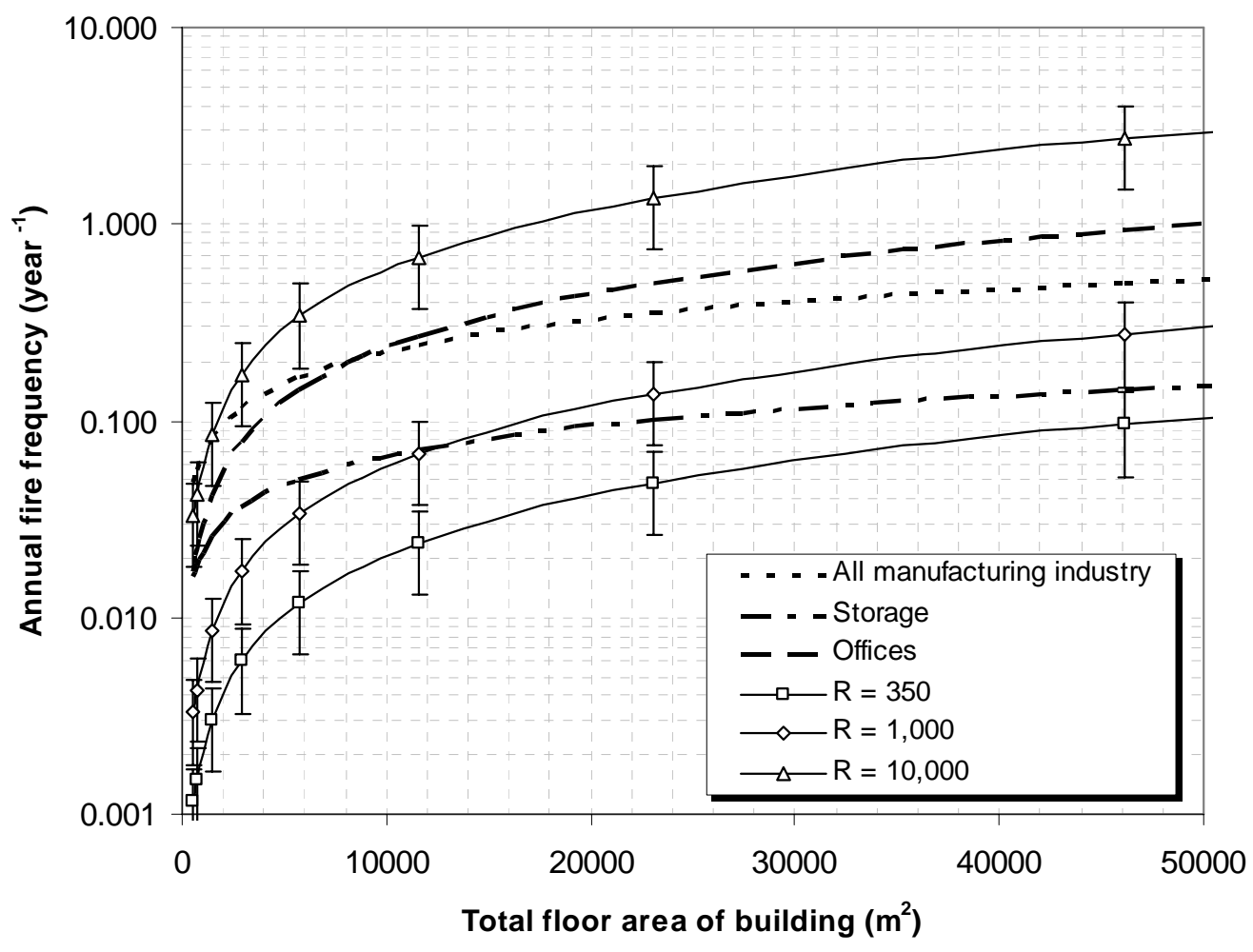

Figure 7. Comparison of fire frequencies between general and parking buildings.

\section{DISCUSSION}

The results from the statistical analysis are from a relatively small sample of data and have a number of limitations. Consequently the findings presented in this paper should be treated with care. Vehicle fires accounted for $3418 / 22777=15 \%$ of the fire calls attended by the New Zealand Fire Service in 2002-2003 [33]. The average of 12 fires per year in parking buildings is therefore only a very small proportion of the total number of recorded fire incidents.

In the three cases of multiple vehicle involvement, the FIRS database did not indicate the level of involvement of additional vehicles and whether they contributed to a significant increase in the heat release rate. Since all three fires occurred in private parking buildings, it was not possible to identify the openness of the buildings and its relationship to a spreading fire. Furthermore, it is not possible to account for the effects of any automatic suppression or fire-fighter intervention on the fire spread to neighbouring vehicles. 
The annual fire frequency in parking buildings has been shown to be related to the annual usage ratio. Only a single estimate of a typical value for the annual usage ratio was available and the value of 350 year $^{-1}$ suggests that a space is only visited once per day on average. This value appears to be low compared to what might be expected for say a busy parking building close to a shopping complex. More data for annual usage ratios is desirable to determine what range of values are reasonable for different types of parking building.

\section{CONCLUSIONS}

During the eight-year period from 1995 to 2003, there were a total of 96 fire incidents involving vehicles or on average 12 vehicle fire incidents each year in New Zealand parking buildings. There were a total of eight vehicles involved in three multiple vehicle fire incidents, which equate to approximately $3 \%$ of total vehicle fire incidents in New Zealand parking buildings.

The four leading causes of vehicle fires in parking buildings were found to be deliberately lit, electrical faults, mechanical failure or malfunction, and carelessness. The average age of vehicles involved in New Zealand parking building fires was 14.3 years old. It was also found that the probability of a vehicle being involved in a parking building fire rises with the increase of the vehicle age.

The frequency of vehicle fires in New Zealand parking buildings was estimated to be $1.71 \times 10^{-7}$ per each vehicle visit. Annual vehicle fire frequencies in New Zealand parking buildings are lower than those in the buildings of other occupancies when annual usage ratio for the parking building is relatively low, and increases with the annual usage ratio.

When a design fire is represented by the $t$-squared fire, the expected growth rate is to be a value between slow and medium growth rate. The peak HRR can vary from approximately $4 \mathrm{MW}$ to $9 \mathrm{MW}$, depending on the amount of energy to be released from the vehicle in consideration. If the ventilation conditions are close to that in a closed car park, the fire spread between vehicles should be considered. 


\section{ACKNOWLEDGEMENTS}

The authors would like to thank Neil Challands of the New Zealand Fire Service for assistance with the FIRS database. The University of Canterbury Fire Engineering programme is supported by the New Zealand Fire Service Commission.

\section{REFERENCES}

1. Watts, J. M., Hall, J. R. Introduction to Fire Risk Analysis. Section 5 / Chapter 1, (DiNenno, P. J. ed.) SFPE Handbook of Fire Protection Engineering ( $3^{\text {rd }}$ ed.), NFPA, Quincy, MA, 2002.

2. Li, Y. Assessment of Vehicle Fires in New Zealand Parking Buildings. MEFE Thesis. University of Canterbury, Christchurch, New Zealand, 2004.

3. New Zealand Building Industry Authority and Standards Association of New Zealand. Approved Document for New Zealand Building Code: Fire Safety Clauses. Standards New Zealand, Wellington, New Zealand, 2000.

4. National Fire Protection Association. NFPA 88A, Standard for Parking Structures. National Fire Protection Association, Quincy, MA, 1998.

5. Ingason, H. An Overview of Vehicle Fires in Tunnels. SP Swedish National Testing and Research Institute, Boras, Sweden, 2001.

6. Shipp, M. "Vehicle Fires and Fire Safety in Tunnels". Tunnel Management International, 5 (3), 2002.

7. National Fire Protection Association. NFPA 204, Guide for Smoke and Heat Venting. National Fire Protection Association, Quincy, MA, 1998. 
8. Mangs, J. and Keski-Rahkonen, O. "Characterisation of the Fire Behaviour of a Burning Passenger Car. Part I: Car fire experiments". Fire Safety Journal, 23: $17-35,1994$.

9. Schleich, J. B., Cajot, L. G., Pierre, M. and Brasseur, M. Development of Design Rules for Steel Structures Subjected to Natural Fires in Closed Car Parks. European Commission, Luxembourg, 1999.

10. Steinert, C. "Experimental Investigation of Burning and Fire Jumping Behavior of Automobiles". VFDB Journal, 4: 163-172, 2000.

11. Shipp, M. P. and Spearpoint, M. J. "Measurements of the Severity of Fires Involving Private Motor Vehicles". Fire and Materials, 19: 143-151, 1995.

12. Stroup, D. W., DeLauter, L., Lee, J. and Roadarmel, G. Passenger Minivan Fire Tests. National Institute of Standards and Technology, Gaithersburg, M.D. USA, 2001.

13. Santrock, J. Project B.14 - Demonstration of Enhanced Fire Safety Technology - Fire Retardant Materials - Part 1: Full Scale Vehicle Fire Tests of a Control Vehicle and a Test Vehicle Containing an HVAC Module. General Motors Corporation, Warren, MI, USA, 2002.

14. Babrauskas V. Heat Release Rates. Section 3 / Chapter 1, (DiNenno, P. J. ed.) SFPE Handbook of Fire Protection Engineering ( $3^{\text {rd }}$ ed.), NFPA, Quincy, MA, 2002.

15. BHP. Fire and Unprotected Steel in Closed Carparks. BHP Melbourne Research Laboratories, Melbourne, 1987.

16. Kitano, T., Sugawa, O., Masuda, H., Ave, T. and Uesugi, H. "Large Scale Fire Tests of 4-Story Type Car Park Part 1: The Behavior of Structural Frame Exposed to the Fire at the Deepest Part of the First Floor". $4^{\text {th }}$ Asia-Oceania 
Symposium on Fire Science and Technology (Tokyo, Japan), May 24-26. pp $527-538,2000$.

17. New Zealand Fire Service. New Zealand Fire Service Fire Incident Reporting System Instruction \& Coding Manual: For Data Collected After 1 July 1995. Planning and Review Division National Headquarters, Wellington, NZ, 1995.

18. Denda, D. "What About Parking Garage Fires". American Fire Journal, 45 (2): 22-25, 27, 1993.

19. Harris, L. M. Survey of Fire Experience in Automobile Parking Structures in the United States and Canada. Marketing Research Associates, Teaneck, NJ, 1972.

20. Joyeux, D., Statistics in Car Parks. Report INC-01/91 - DJ. CTICM Department Incendie et Essais. Saint-Remy-Les-Chevreuse, France, 2001.

21. Whitaker, E. "Vehicle Fires - Looking Behind the Statistics". Fire Prevention, 222: 33-38, 1989.

22. Ahrens, M. U.S. Vehicle Fire Trends and Patterns. National Fire Protection Association, Quincy, MA, 2001.

23. Federal Emergency Management Agency. "Highway Vehicle Fires". Topical Fire Research Series, 2 (4): 1-2, 2001.

24. Tipping, A. What Happens to a Car When it Reaches the End of its Life? Environmental Effects of Car Disposal. Statistics New Zealand, Wellington, 1998.

25. Moore, G. "Vehicle Fires in the United Kingdom - Or 'Tombstone Technology'". Fire International, 137: 22-23, 1992. 
26. Department for Transport, Age of household cars, 1992-1994 and 1999-2001: Regional Trends 38, National Travel Survey, Last updated: 25/2/04, Available online http://www.statistics.gov.uk, Accessed June 2004.

27. Trisko, E. M. "Results of the 1973 National Survey of Motor Vehicles Fires". Fire Journal, 69: 19-27, 1975.

28. Chandler, S. E. and Shipp, M. P. "Channel Tunnel - A Statistical Study of the Fire Incidence in Road Vehicles." Fire Safety Engineering, 2 (3): 10-12, 1995.

29. Christchurch City Council, Parking Strategy for the Garden City. Christchurch City Council, Christchurch, New Zealand, Available online http://www.ccc.govt.nz/parkingstrategy/parkingstrategy.pdf, 2003. Accessed February 2004.

30. Chrest, A. P., Smith, M. S., Bhuyan, S., Iqbal, M. and Monahan, D. R. Parking Structures: Planning, Design, Construction, Maintenance, and Repair. $3^{\text {rd }}$ ed. Chapman \& Hall, New York, 2000.

31. Ramachandran, G. "Probabilistic Approach to Fire Risk Evaluation". Fire Technology, 24 (3): 204-226, 1988.

32. Rasbash, D. J., Ramachandran, D., Kandola, B., Watts, J. M. and Law, M. Evaluation of Fire Safety. John Wiley \& Sons, Ltd, 2004.

33. New Zealand Fire Service. Emergency Incident Statistics 1 July 2002 - 30 June 2003, National Headquarters, Wellington, NZ, 2003. 


\section{NOMENCLATURE}

$\alpha \quad$ Annual fire frequency constant for a particular type of the building, Equation (2).

A Total floor area, $\left(\mathrm{m}^{2}\right)$.

$f \quad$ Vehicle fire frequency per vehicle visit, $\left(\right.$ year $\left.^{-1}\right)$.

$K \quad$ Annual fire frequency constant for a particular type of the building, Equation (2).

$P \quad$ Efficiency of parking, $\left(\mathrm{m}^{2} /\right.$ space $)$.

$R \quad$ Annual usage ratio or turnover ratio. 